A Progress Report on

DOE/ER/45337--5

DE93 003654

\title{
Fundamental Studies of Stress Distributions and Stress Relaxation in Oxide Scales on High Temperature Alloys
}

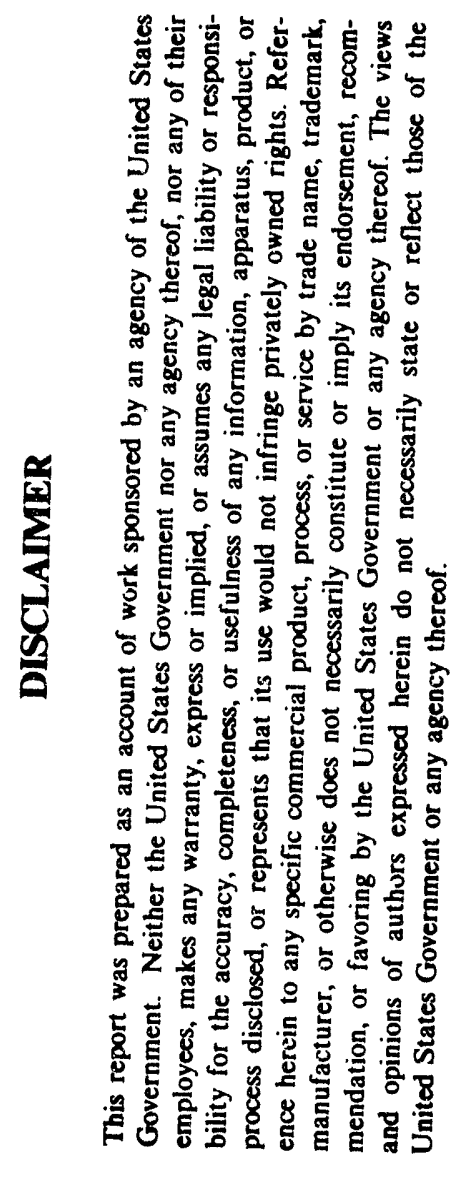

\author{
DE-FG02-88ER45337 \\ submitted to \\ U.S. Department of Energy \\ Office of Basic Energy Science \\ by \\ David A. Shores \\ James H. Stout \\ William W. Gerberich \\ University of Minnesota \\ Corrosion Research Center \\ 221 Church St. \\ Minneapolis, MN 55455
}

June 1992 


\section{TABLE OF CONTENTS}

EXECUTIVE SUMMARY 2

INTRODLCTION

I. EXPERIMENTAL MEASUREMENTS OF STRAIN BY X-RAY DIFFRACTION 3

Background 3

Experimental System 4

Experimental Procedure $\quad 5$

Experimental Results and Discussion $\quad 5$

II. OBSERVATIONS OF SCALE FRACTURE BY ACOUSTIC EMISSION 8

Experimental Procedure $\quad 8$

Results and Discussion 9

III. OBSERVATIONS OF SCALE FRACTURE BY ACOUSTIC EMISSION 11

Mechanical Equilibrium and Deformation of the System 12

Results 13

IV. ADHESION OF NiO BY NANO-INDENTATION AND

$\begin{array}{ll}\text { SCRATCHING TECHNIQUES } & 13\end{array}$

REFERENCES $\quad 14$

Remored APPENDIX I

Preprint of:

"Evaluation of Stresses in Metal/Oxide Systems During High

Temperature Oxidation by X-ray Diffraction ",

by

John G. Goedjen, James H. Stout, Qiti Guo

and David A. Shores

Lewoud APPENDIX II

First page of current publications and pre-prints derived from work supported by this contract 


\section{Fundamental Studies of Stress Distributions and Stress Relaxation in Oxide Scales on High Temperature Alloys}

\section{EXECUTIVE SUMMARY}

Progress in the energy conversion and energy producing technologies is becoming increasingly dependent on the development of alloys resistant to high temperature oxidation. Stresses, which develop in the oxide and underlying metal as an inherent part of the oxidation process, can cause fracture or spallation of the oxide exposing the underlying alloy to renewed oxidation. If a fundamental understanding of the origin and evolution of these stresses were available, future alloy development efforts could take those factors into account to produce alloys with better oxidation resistance. This program is aimed at developing an understanding of the origin and evolution of oxidation-induced strains through a combination of experimental measurements and theoretical modeling studies.

The high temperature $X$-ray diffraction system developed for this program is being successfully employed to make in-situ measurements of the strains which develop during oxidation. This is being applied to the simple model systems, $\mathrm{Ni} / \mathrm{NiO}$ and $\mathrm{Cr} / \mathrm{Cr}_{2} \mathrm{O}_{3}$, and we have begun to isolate and identify factors which control the growth stress and thermal stress components. Our work suggests that the oxide and metal crystalline texture, the anisotropic elastic modulus and anisotropic thermal expansion can have a pronounced effect on strain state of these systems, factors which heretofore have received little attention in the literature.

Acoustic emission is being used to characterize the mechanisms of oxide scale failure (fracture) during oxidation. AE data from experiments using 304 stainless steel as a model alloy are being used to develop a statistical model of the fracture process. The strength of the metal/scale interface is an important fundamental design property that has been difficult to quantify. Using Nano-indentation and scratch techniques developed for characterizing thin film interfaces, an effort has begun to measure the fracture toughness of the metal/scale interface.

Mathematical modelling of the origin and time evolution of growth stresses is an extension and improvement of previous models developed under this contract. The current effort employs a more sophisticated stress analysis and expands the scope to include other stress relaxation processes. The interaction between the modeling studies and the X-ray diffraction measurements provides a natural credibility check to both efforts. 


\section{INTRODUCTION}

The integrity of a metallic component in a high temperature oxidizing environment is dependent on the formation of a protective oxide scale. Growth stresses generated by the oxidation process, and thermal stresses arising from interfacial strains induced by thermal expansion mismatch during temperature excursions can compromise the protective capacity af a scale. These stresses can cause scale fracture, buckling or detachment of the oxide thereby exposing the underlying metal to renewed oxidation. Future alloy development will require a comprehensive understanding of both growth and thermal stresses to insure the protective capacity of oxide scales during service.

The majority of stress measurements made on metal/oxide systems have been made at room temperature, measuring the residual stress state of the system. Residual strains, however, are a complex superposition of the thermal strains that develop upon cooling, and growth strains that develop at elevated temperature as the oxide grows. The contribution which each makes to the stress state of the system can be understood only by independent measurement of the growth and thermal stress components. Residual stress measurements provide a very limited view (and in some cases, an ambiguous view) of the stresses which develop during the oxidation process. Over the course of this contract we have developed a new experimental system for measuring strain insitu during oxidation, and in the present phase we are applying this equipment to measure both the growth strains and the residual strains in simple model systems such as $\mathrm{Ni} / \mathrm{NiO}$ and $\mathrm{Cr} / \mathrm{Cr}_{2} \mathrm{O}_{3}$. This report is divided into four sections which describe (I) experimental measurements of strains in oxidized metals by X-ray diffraction, (II) experimental measurements of scale fracture by acoustic emission, (III) modeling of growth stresses and (IV) experimental measurement of metal/oxide adhesion by nano-indentation and scratching techniques.

\section{EXPERIMENTAL MEASUREMENTS OF STRAIN BY X-RAY DIFFRACTION}

\section{Background}

The existence of stresses is easy to demonstrate, but an evaluation of their origin and magnitude is a more difficult task. Typical average values of measured residual stresses in attached oxides of up to several microns thick are on the order of a few hundred $\mathrm{MPa}$ in compression, (Pivin, Morvan et al., 1983; Aubry, F. Armanet et al., 1988; Guo and Jun, 1989), although some values reported for $\mathrm{Cr}_{2} \mathrm{O}_{3}$ (Stout, Gerberich et al., 1986) and $\mathrm{Al}_{2} \mathrm{O}_{3}$ (Luthra and Briant, 1986; Diot, Choquet et al., 1989) are as high as several thousand MPa. There are very few measurements of the stress that develops simultaneously in the adjoining substrate, (Stout, Gerberich et al., 1986; Diot, Choquet et al., 1989) but in general average values are an order of magnitude smaller and of opposite sign. Efforts to estimate the growth stress by subtracting the 
calculated thermal stress from the measured residual stress have been made. The mathematical models used to calculate the thermal stress are simplistic; they do not account for complicating issues such as creep in the oxide and metal or scale fracture, and they are also dependent on reliable material properties of the oxide and metal. A comprehensive understanding of stresses, and how they develop with time, requires independent determination of the growth and thermal stress components, which can only be made in-situ, during the oxidation process.

\section{Experimental System}

The X-ray sysiem used in this study employs the transmission diffraction geometry. The transmission method has several advantages over traditional reflection techniques such as the $\operatorname{Sin}^{2}(\Psi)$ method. The transmission technique provides a means of making rapid in-situ determinations of elastic in-plane latrice strains in both the oxide and underlying metal; the $\operatorname{Sin}^{2}(\Psi)$ method has been predominantly restricted to measurements in the oxide. The transmission geometry also provides an average measure of the strain throughout the entire sample; reflection techniques measure only the strain at the surface of the sample. The transmission technique therefore provides a more representative average measurement of the strain in the oxide and metal.

The primary components of the X-ray system are depicted in Figure 1. The X-ray source is a Rigaku RU-200 generator with a Mo rotating anode. The generator is run at $50 \mathrm{kV}$ and $15 \mathrm{~mA}$ yielding a primary beam of $750 \mathrm{~W}$ atts. The primary beam is monochromated using a quartz crystal focusing monochromator. The monochromator eliminates the Mo $\mathrm{K} \beta$ peaks, and clearly resolves the Mo $\mathrm{K} \alpha_{1}$ and Mo $\mathrm{K} \alpha_{2}$ peaks. The monochromated beam is collimated with a $500 \mu \mathrm{m}$ gold pinhole aperture.

The specimen is placed at the center of a rotatable ceramic stage and is supported between two sheets of mica. A hole drilled through each mica sheet forms an aperture allowing exposure of the specimen to the beam. The specimen is heated with an electric resistance furnace which is placed over the specimen stage. The furnace, which has a maximum temperature of $1100^{\circ} \mathrm{C}$, is constructed of Kanthal ${ }^{\mathrm{TM}} \mathrm{A} 1$ heating elements and high-grade $\mathrm{Al}_{2} \mathrm{O}_{3}$ ceramics. A $2 \mathrm{~mm}$ hole in the side of the furnace allows the beam to impinge on the sample. The diffracted and direct beams exit through a slit on the opposite side of the furnace. The furnace temperature is controlled by a low voltage programmable temperature controller. The control gas is delivered at the top of the furnace and is exhausted through the X-ray entrance and exit ports. A curved-wire position sensitive detector (PSD) is used to collect the diffraction spectrum. The spectral output of the PSD is processed by a Tracor Northern 1710 multichannel analyzer. 


\section{Experimental Procedure}

A typical experiment consists of three phases: heating, isothermal oxidation, and cooling. During the heating phase the temperature is raised to the desired oxidation temperature in steps using a programmable temperature controller. At each temperature step the temperature is allowed to equilibrate and a diffraction spectrum is taken. A non-oxidizing atmosphere, typically $\mathrm{N}_{2}-$ $10 \% \mathrm{H}_{2}$, is maintained in the furnace during this phase to avoid oxidation. Consequently, only thermal expansion of the metal is measured. Once the desired temperature is reached the oxidation phase is initiated by introducing pure oxygen into the furnace. The diffraction information is continuously collected and stored as oxidation progresses over several hours. The growth strain, if any, will be observed during this period. After the desired oxidation time the cooling phase is initiated. The temperature is reduced in steps, and a diffraction spectrum is taken at each step to monitor the thermal strains generated on cooling.

The lattice spacing, $\mathrm{d}$, for each (hkl) reflection is calculated from the diffraction peak centroid using Bragg's law. The lattice strain is calculated using the familiar equation:

$$
\% \varepsilon=\frac{\left(\mathrm{d}-\mathrm{d}_{0}\right)}{\mathrm{d}_{0}} \cdot 100
$$

where $d_{0}$ is the unstrained ASTM lattice spacing.

\section{Experimental Results and Discussion}

The in-situ X-ray diffraction system has been successfully employed to measure the strain during all phases of the oxidation process - heating, isothermal oxidation, and cooling in the simple systems of $\mathrm{Cr} / \mathrm{Cr}_{2} \mathrm{O}_{3}$ and $\mathrm{Ni} / \mathrm{NiO}$. The in-situ strain measurements on the oxidation of $\mathrm{Cr}$ and $\mathrm{Ni}$ have provided a wealth of information which would not otherwise be available from residual strain measurements. The strain measurements suggest that the strain state in the oxide and metal is a complex function of the oxide morphology, crystalline texture and the substrate orientation. The growth stress, which has often been disregarded in residual stress experiments, can influence the residual strain state of the oxide and metal.

\section{OXIDATION OENI}

The strains observed during the oxidation of a $25 \mu \mathrm{m} \mathrm{Ni}$ foil are presented in Figure 2. Upon heating in $\mathrm{N}_{2}-10 \% \mathrm{H}_{2}$ the annealed $\mathrm{Ni}$ foil expands $1.6 \%$, slightly greater than the expected thermal expansion value of $1.5 \%$ predicted in the literature (dashed line). Shortly after introduction of $\mathrm{O}_{2}$ the oxide, $\mathrm{NiO}$, is observed; simultaneously an increase in tensile strain of approximately $0.8 \%$ is observed in the metal. This strain is equal to the (elastic) strain at yielding of the metal. 
The metal and oxide strains remain relatively constant during the isothermal oxidation period. The oxide is also in tension relative to its normal themal expansion strain of $1.3 \%$ (dashed line).

Prior to these measurements it was thought that the oxide and metal strains develored gradually over time: however, our measurements show that the strain develops very rapidly after introduction of $\mathrm{O}_{2}$. Over the volume of the specimen the forces from the stresses must be balanced, i.e., nominally the oxide is in compression and the metal experiences tension. However, a tensile oxide strain is observed experimentally. The $\mathrm{NiO}$ scale has a duplex structure: a finegrained equiaxed interior zone, and a columnar exterior zone. One possibility is that the growth mechanisms of the two zones may induce different signs of growth stresses. The exterior zone exhibits a crystalline texture, which will affect diffraction intensities. This tensile strain may be the result of preferential diffraction from a portion of the oxide scale. The interior equiaxed zone is randomly oriented and as such some portion of the scale is always in diffracting condition. The measured strans may therefore be dominated by the strain representative of the interior equiaxed zone. A similar observation of a duplex stress state has been made by (Ueno, 1974).

The residual strains, measured at room temperature, suggest that the oxide and metal are both in a stuic of compression. The metal, however, is in tension relative to the initial unoxidized strain state. The in-situ measurements show that the elastic strain limit in the metal was reached during the isothermal oxidation period. These strains are maintained upon cooling to room temperature, thus demonstrating that a simple subtraction of a calculated thermal stress from the measured residual stress does not provide a realistic measure of the growth stress. The experiments also suggest that the initial strain state of the metal, prior to oxidation, can effect the interpretation of the final strain state of the system, an aspect which has been heretofore neglected in residual stress measurements.

The dependence of strain state on oxide and metal thickness was investigated by oxidizing foils of various thickness. The oxidation strain profile for a $125 \mu \mathrm{m} \mathrm{Ni}$ foil is presented in Figure 3. The thicker metal foil exhibits no significant increase in strain during the isothermal oxidation period; the oxide strain is compressive during this period. While the metal strain may be substantial at the metal/oxide interface, the average metal strain is distributed over a greater volume of metal than the $25 \mu \mathrm{m}$ foil, reducing the average measured strain. The residual metal strain is also zero, the residual oxide strain remains in compression. The importance of crystalline texture is again illustrated by the absence of the $\mathrm{NiO}(220)$ and $(200)$ reflections; suggesting that the measured oxide strain may not be representative of the entire oxide scale.

In-situ experiments on the oxidation of $\mathrm{Ni}$ to date suggest that the residual stress in the oxide and metal is a complex function of the growth and thermal stresses. Theses stresses are influenced by the oxide morphology, crystalline texture and the initial stress state of the metal. 


\section{QXIDATION OF CR2 23}

Oxidation studies on $\mathrm{Cr}$ have been confined to single crystals due to a lack of high quality polycrystalline materials. The single crystal experiments provide a unique opportunity to study the effect of crystal orientation on the stress state of the system. Initially experiments were performed on single-crystal $\mathrm{Cr}$ oxidized on the (100) face. These experiments have been extended to examine the effect of substrate thickness on the state of stress. Experiments on the oxidation of the $\mathrm{Cr}$ (111) face have also been carried out to establish the effect of crystal orientation on the stress state of the system.

Typical results for $\mathrm{Cr}$ oxidized on the (100) face are illustrated in Figure 4. A small tensile strain in the metal (relative to the unstrained thermal expansion strain) is observed once the oxidation temperature is reached, but before oxygen is introduced. This strain is believed to result from a thin oxide layer formed during heating due to the incomplete suppression of oxidation. Upon introduction of $\mathrm{O}_{2}$ an increase in tensile strain is immediately observed in the metal. The oxide, which is observed shortly after the introduction of oxygen, develops a tensile strain relative to the unstrained thermal expansion value. Each of the oxide reflections exhibits a different thermal strain at the oxidation temperature. The $(11 \cdot 0)$ and $(10 \cdot 4)$ reflections are in tension, the $(11 \cdot 6)$ is in compression. As oxidation proceeds the strain in both the oxide and metal remain relatively constant. Upon cooling the metal maintains a residual tensile strain. The $(11 \cdot 0) \mathrm{Cr}_{2} \mathrm{O}_{3}$ reflection exhibits a small tensile residual strain. This is also the direction of greatest thermal expansion and the most elastically compliant direction in the hexagonal crystal structure. The $(10 \cdot 4)$ and $(11 \cdot 6)$ $\mathrm{Cr}_{2} \mathrm{O}_{3}$ reflections exhibit a residual compressive strain. These two planes have a lower thermal expansion than the $(11 \cdot 0)$, and are elastically stiffer than the $(11 \cdot 0)$.

Oxidation experiments on $\mathrm{Cr}$ single-crystals oxidized on the (111) face are summarized in Figure 5. Again, the metal exhibits a small tensile strain increase immediately after introduction of $\mathrm{O}_{2}$ into the system. The oxide strain maintains both tensile strains in the $(11 \cdot 6)$ reflection and compressive strains in the $(11 \cdot 0)$ and $(10 \cdot 4)$ reflections. The metal maintains a residual tensile strain on cooling. A residual compressive strain is measured in each of the three oxide reflections.

Almost all of our previous experiments, including the most recent ones, indicate that growth stresses developed in both metal and oxide are constant during the isothermal oxidation period. The growth stress appears to be independent of scale thickness. ${ }^{*}$ This suggests that the growth stress in the $\mathrm{Cr} / \mathrm{Cr}_{2} \mathrm{O}_{3}$ system reaches a threshold at which some relaxation process, such

* Earlier theoretical studies, which did not take intc account oxide growth mechanisms, suggested that the magnitude and distribution of stresses in the metal and oxide would depend on the ratio of metal/oxide thicknesses. 
as creep or yielding, determines the stress state. The mechanism of relaxation merits further experimental studies, and theoretical modeling studies are presently considering this issue

The complex nature of the stress state is exemplified by the variability in the oxide strain with crystalline direction. While the metal strain is consistently tensile, both compressive and tensile strains have been observed in the oxide. The oxide strains are believed to result from variations in oxide texture, metal substrate orientation and the anisotropic behavior of the thermal expansivity and elastic modulus of the oxide. The results obtained to date illustrate the complex evolution of stresses during the oxidation period and the important influence of the growth stress on the residual stress. A determination of the residual stress alone reveals little about the stress state encountered during oxidation.

\section{OBSERVATIONS OF SCALE FRACTURE BY ACOUSTIC EMISSION}

Under practical oxidizing conditions, stresses induced by the scale growth process and particularly by thermal expansion mismatch during thermal cycling may be sufficient to cause cracking and spalling of the protective oxide scale. (Stringer, 1970; Hancock and Hurst, 1974; Baxter and Natesan, 1983) Some work has been done to identify practical ways of improving the oxide scale adherence to the metallic substrate, (Stott, 1988), and to identify the basic factors that determine the scale cracking/spalling process. (Evans, 1988; Evans, 1989)

Oxide scales formed on different metals or alloys behave differently with regard to their resistance to spallation. Some of them have very good resistance to cracking and spalling, e.g., the MCrAlY - type alloys, some do not. The oxide scale formed on 304 stainless steel is an example of one that is easy to crack and spall, therefore it has been chosen here as a model of cracking and spalling processes. Acoustic emission has been applied to investigate the fracture process of oxide scales formed on 20Cr-25Ni-Nb stabilized stainless steel, (Evans, 1988; Bennett, Buttle et al., 1989) but no similar study of the behavior of 304 stainless steel scales has been found. The purpose of this work is to study the fracture of the oxide scales formed on 304 stainless steel.

\section{Experimental Procedure}

The acoustic emission technique (AE), which is a very useful tool in the study of the fracture of brittle materials, ${ }^{*}$ was used to monitor scale cracking and spallation during experiments involving isothermal oxidation and subsequent controlled cooling to room temperature. SEM was used to characterize the scale cracking morphology and spalled regions on the oxide scale.

* (Desai and Gerberich, 1975; Huang, Lin et al., 1984; Khanna, Jha et al., 1985; Jha, Raj et al., 1986; Khanna, Jha et al., 1986; Christl, Rahmel et al., 1987; Bennett, Buttle et al., 1989) 
Samples of 304 stainless steel $^{*}$ were cut from a bar into disks $9.5 \mathrm{~mm}$ diameter and 0.5 $\mathrm{mm}$ in thickness. The surface of the samples were polished through 600 grit silicon carbide paper. The sample is spot-welded to a platinum wire and suspended in the oxidation chamber. The platinum wire also acts as the acoustic signal waveguide. A schematic of the experimental setup is presented in Figure 6.

The samples were isothermally oxidized at $800^{\circ} \mathrm{C}$ for 20 hours in pure $\mathrm{O}_{2}$ flowing at 50 $\mathrm{cc} /$ minute, then furnace cooled to some intermediate temperature and held at that temperature for 24 hours before being cooled to room temperature. After the initial isothermal oxidation period the reaction chamber was nushed with Ar to suppress further oxidation. Acoustic emission signals generated at the surface of the sample are transmitted to the $\mathrm{AE}$ transducer by the $\mathrm{Pt}$ waveguide, amplified to a total gain of the $95.6 \mathrm{~dB}$ and subsequently processed using the AET 5000 system.

\section{Results and Discussion}

After 20 hours isothermal oxidation at $800^{\circ} \mathrm{C}$ in flowing pure oxygen, a scale about $10 \mu \mathrm{m}$ thick, containing $\mathrm{Cr}_{2} \mathrm{O}_{3}$ and spinels, formed on the sample. In all the experiments, only a few (insignificant number) $\mathrm{AE}$ events were recorded during the isothermal stage, indicating that the growth stress is not large enough to fracture the scale. Figure 7 shows the AE result of an experiment in which the sample was furnace cooled directly to rocm temperature. In this experiment, the scale started to crack and spall continuously when the sample was cooled to a relatively low temperature (about $300^{\circ} \mathrm{C}$ ). Since the thermal stress is approximately proportional to the cooling amount $(\Delta \mathrm{T})$,(Tien and Davidson, 1974) it appears that a certain level of stress is needed to start the scale fracture process. As cooling continued, the amount of cracking and spalling (as represented by the rate AE events) kept increasing to a peak value at approximately $150^{\circ} \mathrm{C}$, then decreased to very low level when the temperature reached room temperature. It should be noticed, however, that even after the sample was at room temperature, additional AE events were detected, although no additional stresses were applied to the specimen. One possible explanation is that some cracks continued to grow slowly under the static stress until they reached critical size for fracture.

For other experiments, cooling was interrupted for 24 hours at various temperatures between $300^{\circ} \mathrm{C}$ and room temperature. Figure 8 shows the results of an experiment in which the sample was held at $200^{\circ} \mathrm{C}$ for 24 hours. It can be seen that $\mathrm{AE}$ events were initiated at approximately $300^{\circ} \mathrm{C}$, as before, but the events stopped shortly after the temperature stabilized at $200^{\circ} \mathrm{C}$, implying that the scale fracture process had been almost stopped. Small numbers of $\mathrm{AE}$

* The nominal composition of 304 stainless steel is $\mathrm{i} 8.0-20.0 \% \mathrm{Cr}, 8.00-10.50 \% \mathrm{Ni}$, $<2.00 \% \mathrm{Mn},<0.045 \% \mathrm{P},<0.030 \% \mathrm{~S},<1.00 \% \mathrm{Si}, 0.08 \% \mathrm{C}$, balance Fe. 
events were recorded during holding, indicating the possibility of slow crack growth during this period. When cooling was resumed after 24 hours, additional large numbers of events were recorded, giving rise to a steep peak, indicating that the extensive scale cracking and spalling started again at a small additional $\mathrm{JT}$. Figure 9 shows the results of a $100^{\circ} \mathrm{C}$ holding experiment, and again the $\mathrm{AE}$ events were suspended during the hold period. It should be noticed that $2(0)^{\circ} \mathrm{C}$ is low enough to suppress substrate creep. Therefore scale cracking and spalling will be the only way of releasing stresses.

Since cracking and spalling of the scales continued over a range of temperature, no single critical fracture stress applies to the entire specimen, in agreement with the proposal by (Evans, 1988). As Evans suggested, the entire scale may be viewed as many small regions, some of them are easy to fracture, some are not. At some critical stress level (associated with $\Delta \mathrm{T}$ ), the weakest regions will spall away, some regions will crack, and some regions remain intact. The stress will be completely relaxed in the spalled area, partially relaxed in the cracked area, and completely sustained in the intact regions. These features are shown in Figure 10, an SEM micrograph of an oxidized 304 stainless steel. This analysis shows that the oxide scale structure is not homogeneous throughout the entire sample, and therefore the scale will fracture over a range of stresses, associated with a range of $\Delta \mathrm{T}$.

From the experimental results it can be seen that the growth stress may not play a significant part in the scale fracture process since only a very small number of $A E$ events were recorded during the isothermal oxidation stage. However, the small number of cracks produced in that stage could act as the nuclei for later cracking and spallation during cooling. The continuation of cracking, after the specimen has reached a constant temperature and therefore is in a state of static or diminishing stress, is not well understood. One possibility is that some existing cracks (flaws) may continue to propagate slowly under the remaining stresses. A few such cracks may reach critical size, triggering a few cracking events. When cooling is resumed, the increased stress will activate a much larger number of near-critical size flaws, producing additional AE events.

The model of the cracking and spallation processes, alluded to above, which is based on $\Delta \mathrm{T}$ generating a stress that rises to the local fracture stress is somewhat naive. First, the stress directly related to $\Delta \mathrm{T}$ is biaxial and strictly applies at a flat metal/oxide interface. In reality, the stresses are likely to be triaxial, and the stress in the thickness dimension may be a crucial component of the fracture stress. Such considerations will be particularly important near edges, comers and non-planar interfaces. Secondly, as shown in the preceding section, the magnitude of the local stress also depends on the crystallographic orientations of the metal and oxide and the relationships between crystal directions and elastic moduli of the metal and oxide. Thus while an average stress may be readily calculated, the magnitude of the local stress may deviate considerably from the average. Thirdly, since the oxide is a brittle material, the fracture stress of a local region 
will be controlled by the size of local thaws. Such tlaws may include scale morphology teatures, such as grain boundaries or static crack tips. Fourthly, the interaction between adjacent regions would seem to be important and quite complicated. On the one hand, a fracture in one region may introduce a larger flaw (the advancing crack tip) in an adjacent region. This would have the effect of allowing fracture in the adjacent region at a lower stress. On the other hand, cracking and spalling invariably lowers the local stress in the region experiencing the crack, but the reduction of stress there may also allow a relaxation of the stresses in adjacent regions. Thus cracking events in adjacent regions may be expected to be interdependent. Fifthly, as noted above, cracking can be time dependent at a fixed stress. The foregoing discussion suggests some factors to be considered in the development of a model not yet expressed in mathematical terms. The concept of viewing the oxide scale as comprised of a field of small regions or cells, each described in terms of a preexisting flaw, a state of stress dependent on temperature and crystal orientation and a mechanical connection (interaction) to adjacent regions seems like a fruitful approach. A deterministic solution of such a problem is probably not feasible because of the difficulty of specifying structural and morphological parameters. However, the large number of cracking events invites a statistical approach to solving such a problem. This is an issue we will continue to pursue in the coming year.

\section{MOdeling OF GROWTH STRESS in a THIN METAl Plate due to HIGH TEMPERATURE OXIDATION}

The objective of this study is to model the distribution of stresses in an adherent oxide scale and its metal substrate and to describe the evolution of these stresses with time as the scale grows isothermally. The $\mathrm{Cr} / \mathrm{Cr}_{2} \mathrm{O}_{3}$ system was chosen to provide explicit calculated values for comparison with experimental in-situ X-ray measurements. As the scale grows at the oxidation temperature, the misfit between the scale and the metal substrate is a source of strain, some of which may be accommodated by free expansion into the gas phase and some is accommodated by inducing stresses in the scale and substrate. These stresses are subject to partial relaxation by plastic deformation, i.e., yielding if the stress is high enough, and by creep at lower stresses. Thus, as the scale grows, it may be expected that the stresses will evolve in a complicated manner. This work builds upon and extends an earlier study in which the source of strain (at a fixed scale thickness) was the thermal expansion misfit between the scale and metal upon cooling (Bames, Goedjen, et al., 1989). 


\section{Mechanical Equilibrium and Deformation of the System}

Since the $\mathrm{Cr}$ samples used in the $\mathrm{X}$-ray aiffraction experiments are thin flat plates and the measurements are focussed on the middle portion of the plate to avoid edge effects, a geometrically simple model, as illustrated in Figure 11 a can be used. The mechanical force balance of the system, as illustrated in Figure 11a, requires:

$$
\frac{d}{d t}\left[\sigma_{o x}(t) b_{o x}(t)+\sigma_{s b}(t) b_{s b}(t)\right]=0
$$

where $t$ is time, $b_{o x}$ and $b_{s b}$ denote the oxide and substrate thickness, respectively. In expanded form,

$$
\dot{\sigma}_{\mathrm{ox}} b_{\mathrm{ox}}+\dot{\sigma}_{\mathrm{sb}} b_{\mathrm{sb}}+\dot{b}_{\mathrm{ox}} \sigma_{\mathrm{ox}}+\dot{\mathrm{b}}_{\mathrm{sb}} \sigma_{\mathrm{sb}}=0
$$

For $\mathrm{Cr}_{2} \mathrm{O}_{3}$, the rate of stress growth and relaxation is given by Hook's law

$$
\dot{\sigma}_{\mathrm{ox}}=\mathrm{H}_{\mathrm{ox}} \dot{\varepsilon}_{\mathrm{ox}}^{\mathrm{e}}=\left(\dot{\varepsilon}-\dot{\varepsilon}_{\mathrm{ox}}^{\mathrm{vp}}\right)
$$

where $\mathrm{H}_{\mathrm{ox}}$ is the biaxial elastic modulus defined by

$$
\overline{\mathrm{H}}_{\mathrm{ox}}=\left[\frac{\mathrm{E}}{1-\mathrm{v}}\right]_{\mathrm{ox}}
$$

$\dot{\varepsilon}_{\mathrm{ox}}^{\mathrm{vp}}$ is the visco-plastic strain rate, and $\dot{\varepsilon}$ is the overall in-plane strain of the system. The total accumulated stress also depends on the misfit strain $\varepsilon_{\text {sb }}^{*}$ between the scale and the substrate:

$$
\sigma_{\mathrm{ox}}=H\left(\varepsilon-\varepsilon_{\mathrm{ox}}^{\mathrm{vp}}-\varepsilon_{\mathrm{sb}}^{*}\right)
$$

The misfit strain is defined as:

$$
\varepsilon_{\mathrm{sb}}^{*}=\frac{(\mathrm{PBR}-1)}{3}
$$

where PBR is the Pilling-Bedworth Ratio. For $\mathrm{Cr}$, the total stress is only dependent on the elastic strain 


$$
\sigma_{\mathrm{sb}}=H\left(\varepsilon-\varepsilon_{\mathrm{sb}}^{\mathrm{vp}}\right)
$$

The creep of $\mathrm{Cr}$ and $\mathrm{Cr}_{2} \mathrm{O}_{3}$ are assumed to be described by the power-law mechanism defined by

$$
\dot{\varepsilon}^{\mathrm{vp}}=\mathrm{A} \frac{\mu b}{\mathrm{kT}} \mathrm{D}\left(\frac{\sigma}{\mu}\right)^{\mathrm{n}}
$$

where $\mathrm{A}$ and $\mathrm{n}$ are constants, $\mu$ is the shear modulus, $b$ is Burger's vector, $\mathrm{T}$ is temperature and $\mathrm{D}$ is the self-diffusion coefficient. To calculate $\dot{\varepsilon}$ and $\dot{\sigma}$ the growth rate of the scale must also be specified. The parabolic growth equation is used to model the scale growth rate for the $\mathrm{Cr} / \mathrm{Cr}_{2} \mathrm{O}_{3}$ system

$$
\dot{b}_{\mathrm{ox}}=\frac{\mathrm{K}_{\mathrm{p}}}{\mathrm{b}_{\mathrm{ox}}}
$$

where $\mathrm{K}_{\mathrm{p}}$ is the parabolic rate constant. The recession of the $\mathrm{Cr} / \mathrm{Cr}_{2} \mathrm{O}_{3}$ interface can be calculated from the PBR of the system and the misfit strain defined above.

\section{RESULTS}

The Runge-Kutta scheme is employed to numerically integrate the rate equations for scale growth and the visco-plastic strains and stresses. In particular, the oxidation of a thin $\mathrm{Cr}$ plate, 2 mm thick, at $1200^{\circ} \mathrm{C}$ and $1400^{\circ} \mathrm{C}$, was considered using the data for scale growth from (Birks and Meier, 1988) and the power-law creep data from (Frost and Ashby, 1982). These high temperatures were selected for a preliminary evaluation of the role of creep during oxidation. The calculated stress relaxation in the scale and the scale thickness are plotted in Figure $11 \mathrm{~b}$.

Relaxation of the compressive stress in the scale occurs within $10^{5}$ seconds $(27.77 \mathrm{hr}$ ) during oxidation for both temperatures. As discussed by (Frost and Ashby, 1982), for a ratio of shear stress to shear modulus over $10^{-2}$, the predominant deformation mechanism is controlled by dislocation glide. The broad stress range encountered during relaxation dictates that constitutive equations which account for dislocation glide be incorporated into future modeling.

\section{ADHESION OF NiO ON Ni BY NANO-INDENTATION AND SCRATCHING TECHNIQUES}

As discussed by (Atkinson and Guppy, 1991), there are several techniques for the measurement of the adhesion of thermally grown oxide scales to their substrates. However, none of them is capable of determining the true fracture toughness of the interface. For scale layers less 
than $10 \mu \mathrm{m}$ thick, micro-iardness indentation and scratching tests were used to obtain the information on metal/oxide adhesion (Atkinson and Guppy, 1991). For scale layers less than 1 $\mu \mathrm{m}$ thick, no such measurements have been reported. (Venkakaraman and Gerberich, 1992) have examined the work of adhesion between the film and substrate for the $\mathrm{Cr} / \mathrm{Al}_{2} \mathrm{O}_{3}$ thin film system using the nano-scratching test technique.

In the present study the nano-indentation technique has been applied to a $5 \mu \mathrm{m}$ thick $\mathrm{NiO}$ scale grown on pure $\mathrm{Ni}$ (oxidized for $30 \mathrm{~min}$ in $\mathrm{O}_{2}$ at $900^{\circ} \mathrm{C}$ and air cooled to room temperature). The purpose was to measure the interfacial fracture toughness of the metal/oxide interface. The indentation and scratching tests on this sample were performed using the Nano-Indentor ${ }^{\circledR}$ equipment at room temperature. A conical indenter with a tip curvature of approximately $5 \mu \mathrm{m}$ is first driven vertically into the $\mathrm{NiO}$ scale. As seen in this SEM micrograph, Figure 12, the indentation causes severe plastic deformation of the $\mathrm{Ni}$ substrate and fracture of the scale along the oxide grain boundaries. The scale has a duplex structure with an exterior columnar scale with grains $1.5 \mu \mathrm{m}$ in diameter, and an equiaxed interior oxide.

An SEM micrograph of two scratch tracks from the indentor tests performed on the same sample are shown in Figure 13. Track (A) is from a scratch made with a maximum load $0.12 \mathrm{~N}$ to a depth of $1.5 \mu \mathrm{m}$ into the scale, the lower scratch was made with a maximum load $0.22 \mathrm{~N}$ to a depth of $2.7 \mu \mathrm{m}$. Mode I cracking of the scale is clearly seen within the scratch running perpendicular to the scratch direction. Oxide spallation has occurred on the lower track (deeper scratch) exposing the interior layer of the duplex oxide structure. These results will be quantitatively analyzed to characterize the fracture properties of the metal/oxide system. Further tests will be performed on the $\mathrm{Ni} / \mathrm{NiO}$ and other systems with various scale thicknesses using indentors with smaller tip curvature.

\section{REFERENCES}

Atkinson, A. and R. Guppy (1991) Materials Science and Technology, 7, 1031-1041.

Aubry, A., F. Armanet, G. Beranger, J.L. Lebrun, et al. (1988) Acta Metallurgica, 36, 2779.

Barnes, J. J., J. G. Goedjen and D. A. Shores (1989) Qxidation of Metals, 32 449-469.

Baxter, D. J. and K. Natesan (1983) Review of High Temperature Materials, 5, 149-250.

Bennett, M. J., D. J. Buttle, P. D. Colledge, J. B. Price, et al. (1989) Materials Science and Engineering, A120, 199-206.

Birks, N. and G. H. Meier (1988) "Introduction to High Temperature Oxidation of Metals", E. Arnold ed.,

Christl, W., A. Rahmel and M. Schutze (1987) Materials Science and Engineering, 87, 289-293. Desai, J. D. and W. W. Gerberich (1975) Engineering Fracture Mechanics, 7, 153-165. 
Diot, C., P. Choquet and R. Mevrel (1989) "International Conference on Residual Stresses", S.

D. G. Beck ed., Elsevier Applied Science, London,

Evans, H. E. (1988) Materials Science and Technology, 4, 415-420.

Evans, H. E. (1989) Materials Science and Engineering, A 120, 139-146.

Frost, H. J. and M. F. Ashby (1982) "Deformation-Mechanism Maps" Pergamon Press, New York.

Guo, Z. J. and Z. Y. Jun (1989) Materials Science and Engineering,A120, 245.

Hancock, P. and R. C. Hurst (1974) "Advances in Corrosion Science and Technology", M. G.

Fontana and R. W. Staehle ed., Plenum Press, New York, 1-84.

Huang, T. T., Y. C. Lin, D. A. Shores and E. Pfender (1984) Journal of the Electrochemical

Society, 131, $2191-2196$.

Jha, B. B., B. Raj and A. S. Khanna (1986) Qxidation of Metals, 26, 263-273.

Khanna, A. S., B. B. Jha and Baldev Raj (1985) Oxidation of Metals, 23, 159-176.

Khanna, A. S., B. B. Jha and Baldevraj (1986) Qxidation of Metals, 27, 95-102.

Luthra, K. L. and C. L. Briant (1986) Oxidation of Metals, 26, 397.

Pivin, J. C., J. Morvan, D. Mairey and J. Mignot (1983) Scripta Metallurgica, 17, 179.

Stott, F. H. (1988) Materials Science and Technology, 4, 431-438.

Stout, J. H., W. W. Gerberich, S. Lin and M. Lii (1986) "Fundamental Aspects of High

Temperature Corrosion II", G. J. Yurek, D. A. Shores ed., The Electrochemical Society, Pennington, NJ,

Stringer, J. (1970) Corrosion Science 10, 513-543.

Tien, J. K. and J. M. Davidson (1974) "Stress Effects and the Oxidation of Metals", J. V.

Cathcart ed., The Metallurgical Society of AIME, 201-206.

Ueno, T. (1974) Transactions of the Japan Institute of Metals, 15, 167.

Venkakaraman, S. and W. W. Gerberich (1992) "Annual National Meeting of the American Ceramics Society", Minneapolis, MN, 


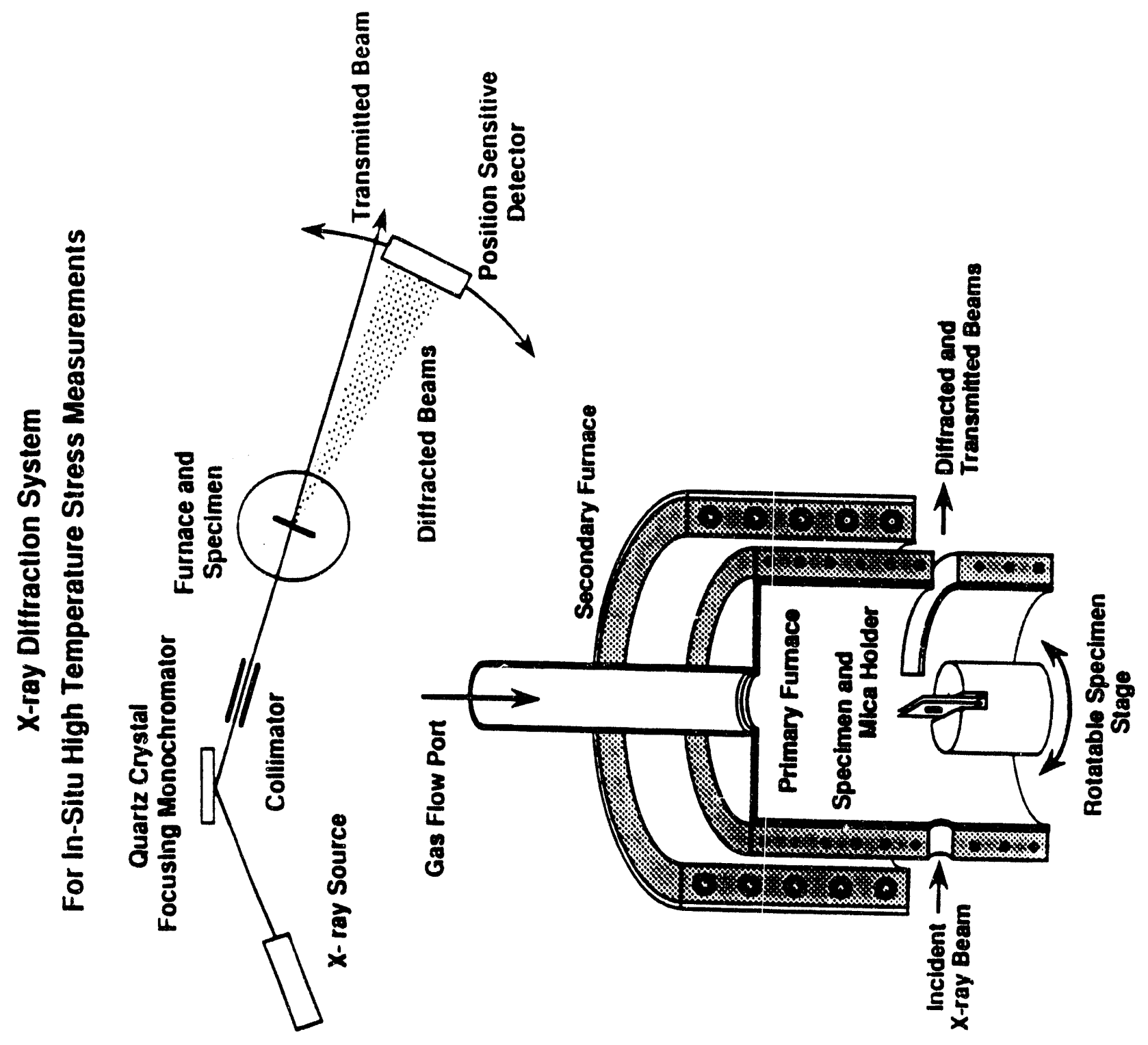

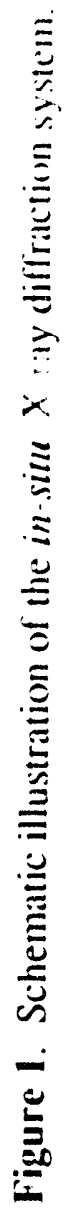




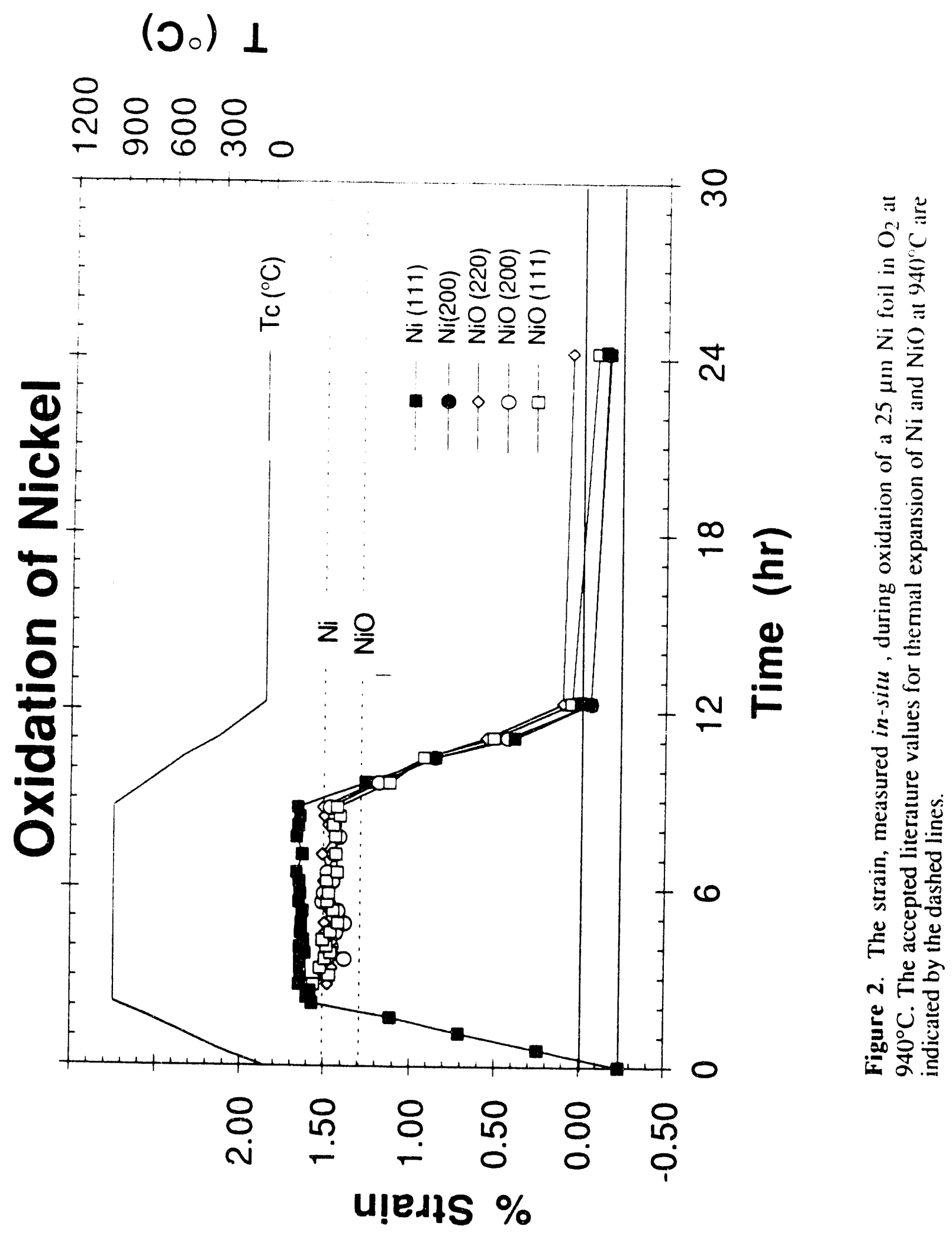




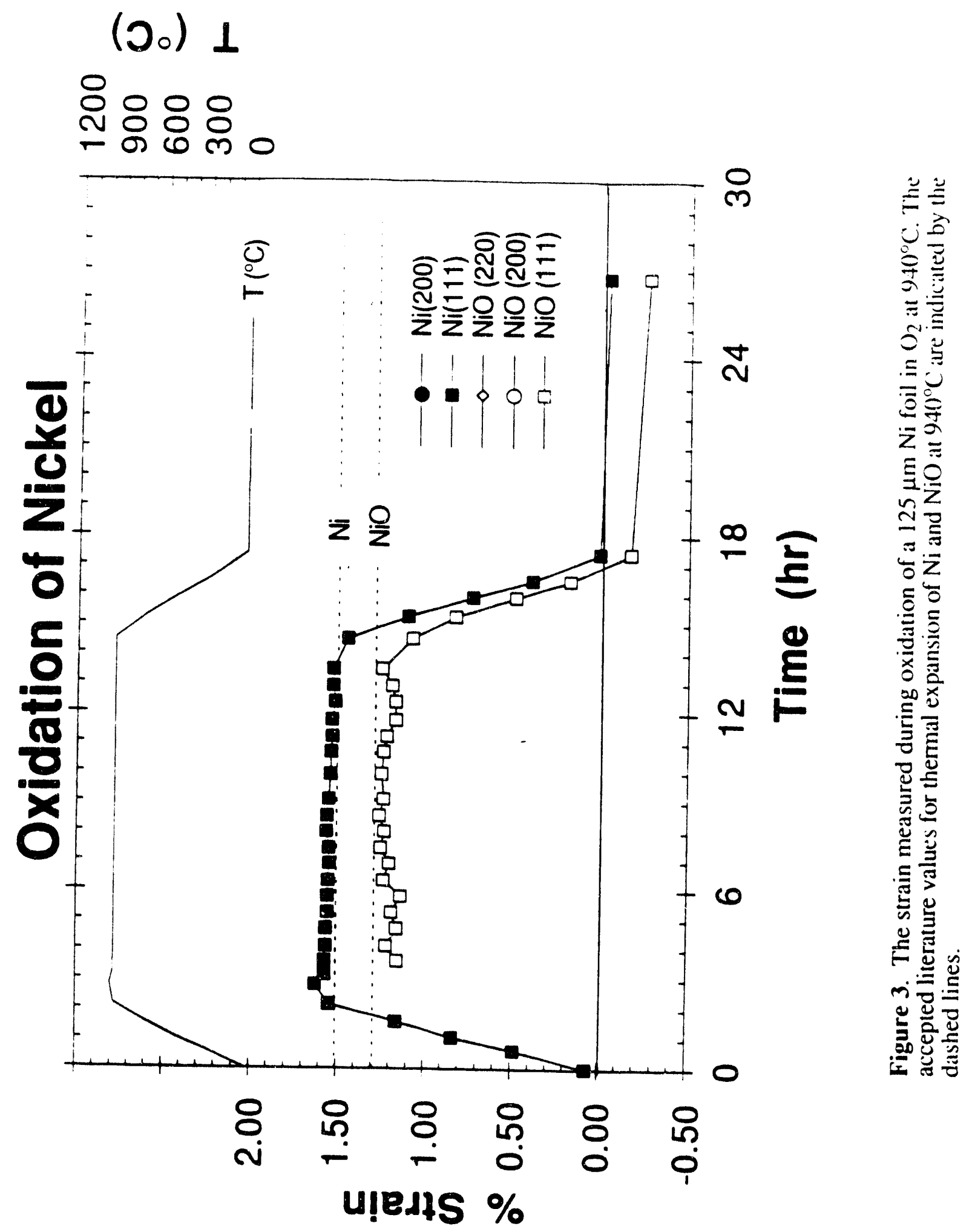




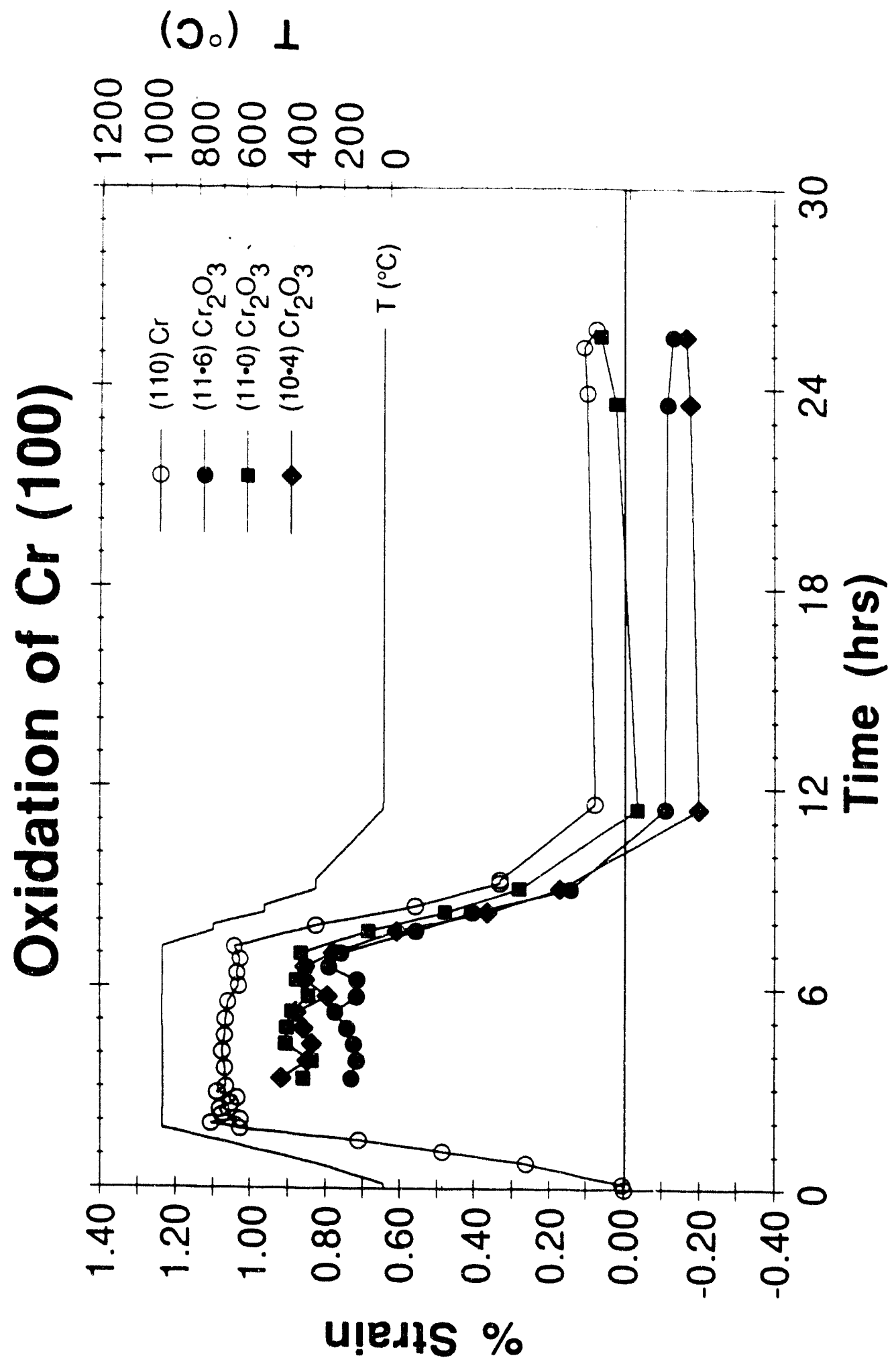

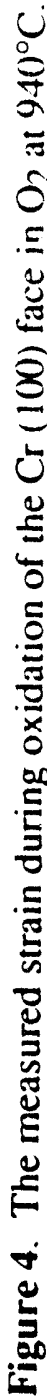




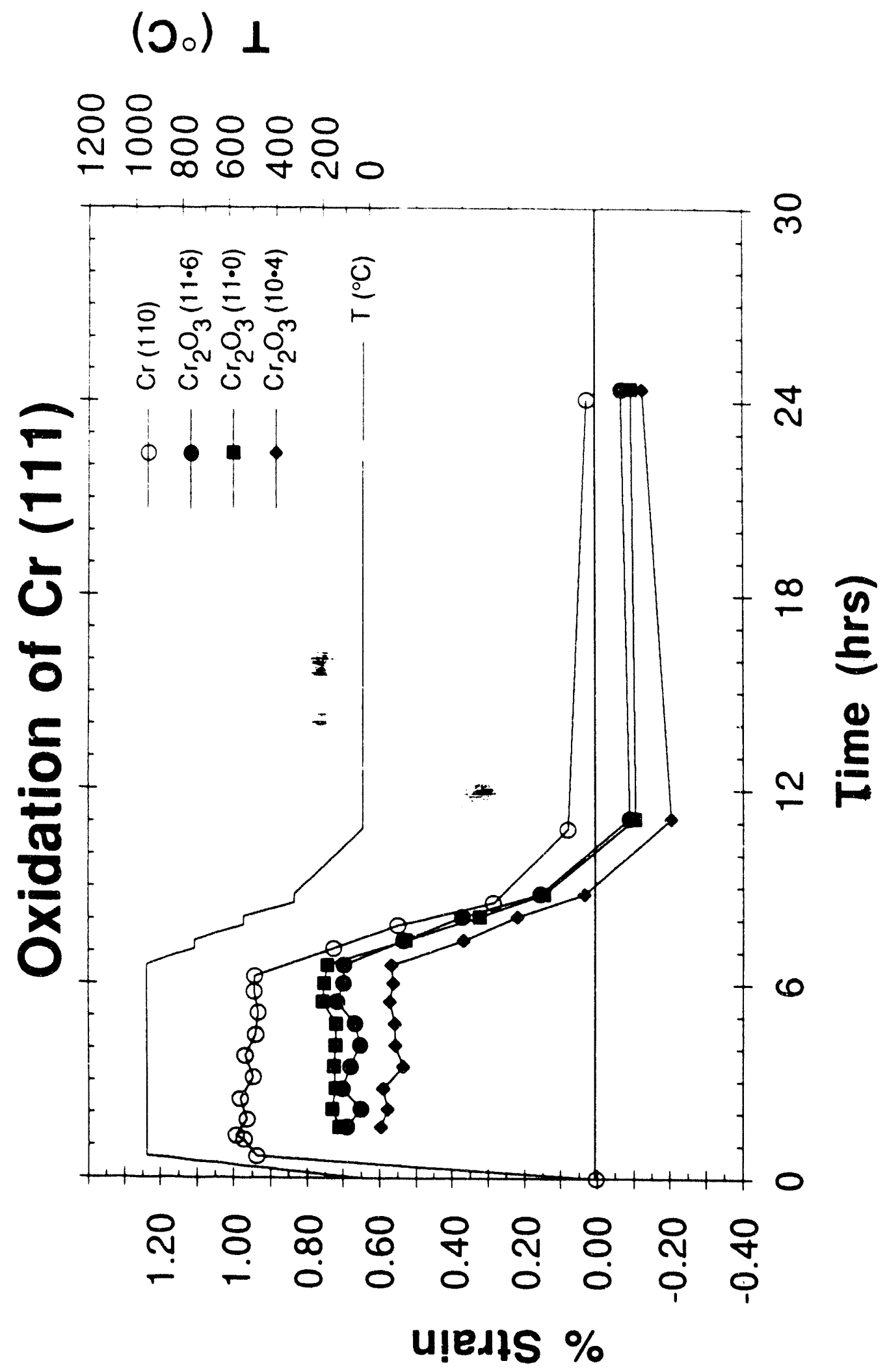

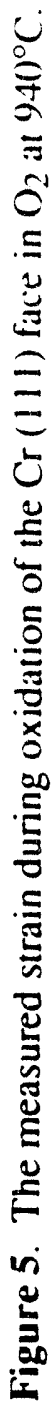




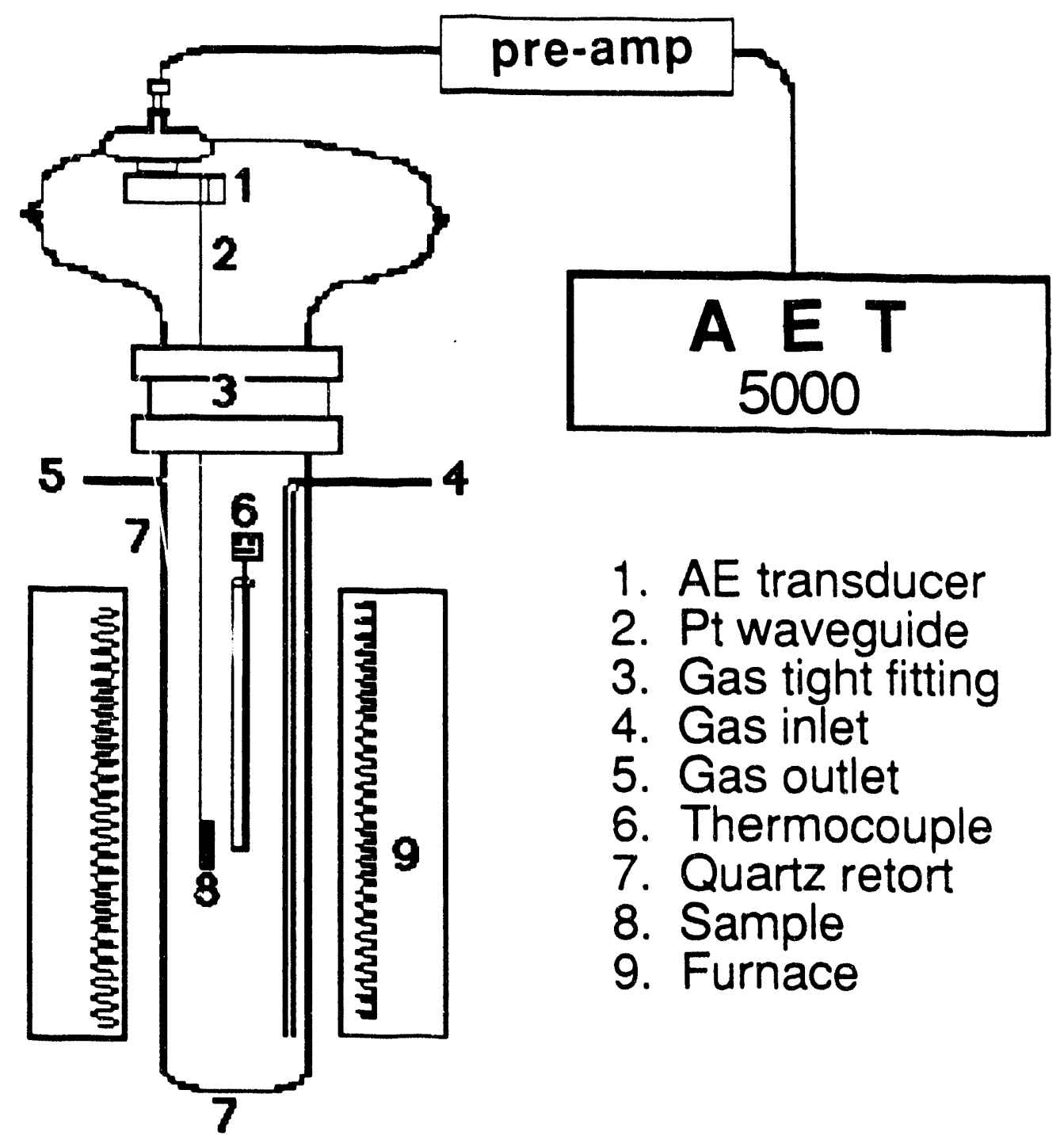

Figure 6. Schematic illustration of the acoustic emission system. 
Temperature $\left({ }^{\circ} \mathrm{C}\right)$

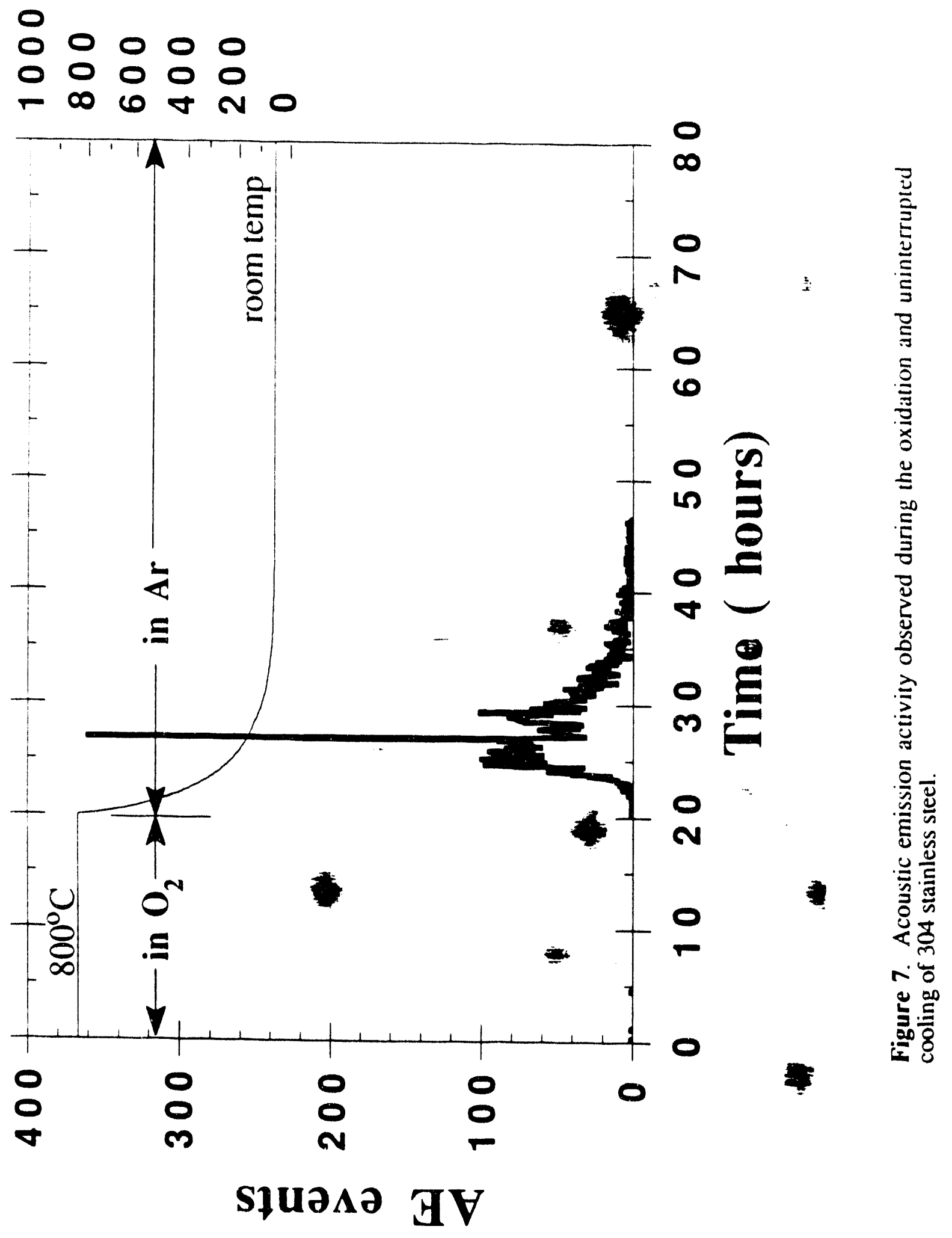




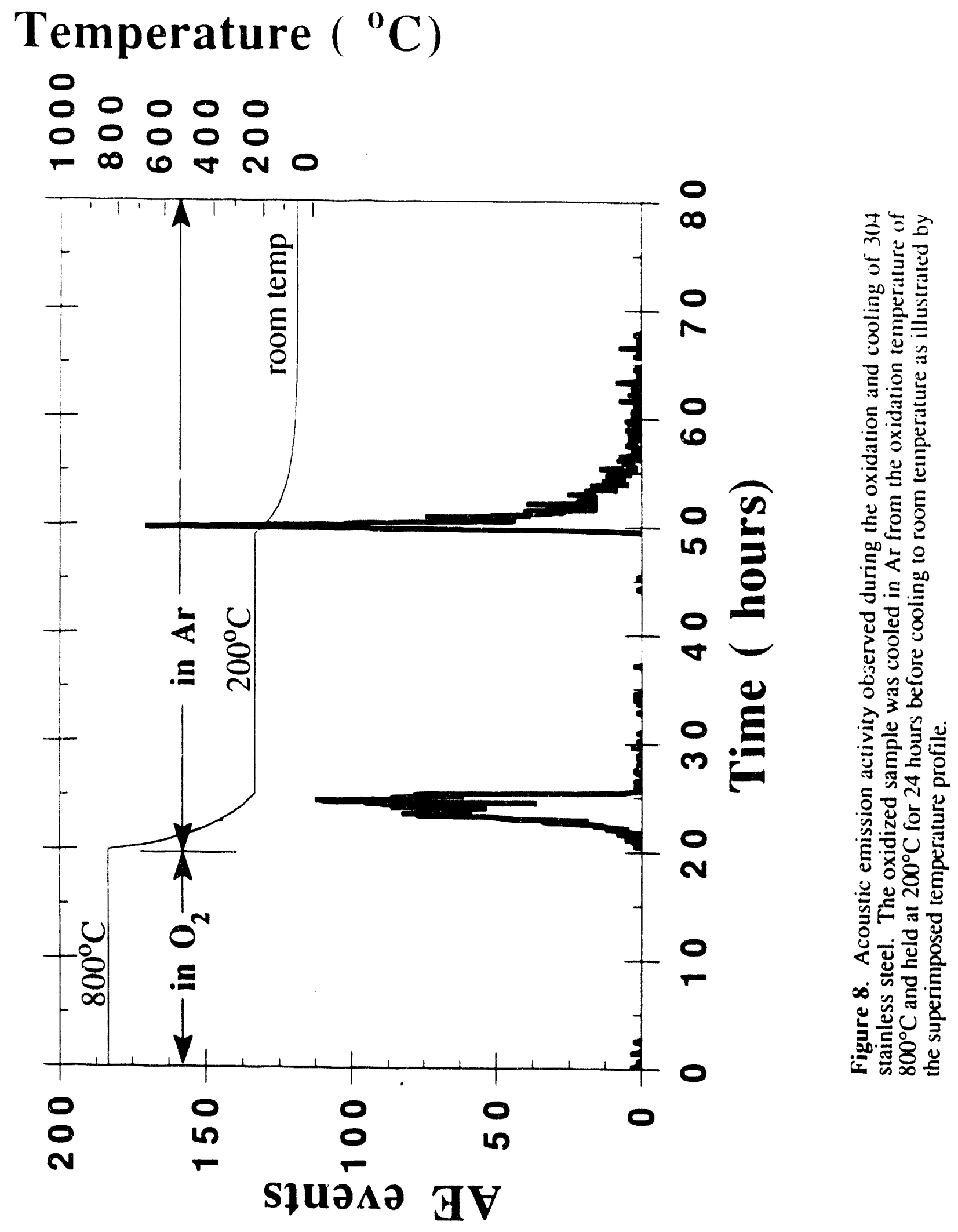




\section{Temperature $\left({ }^{\circ} \mathrm{C}\right)$}
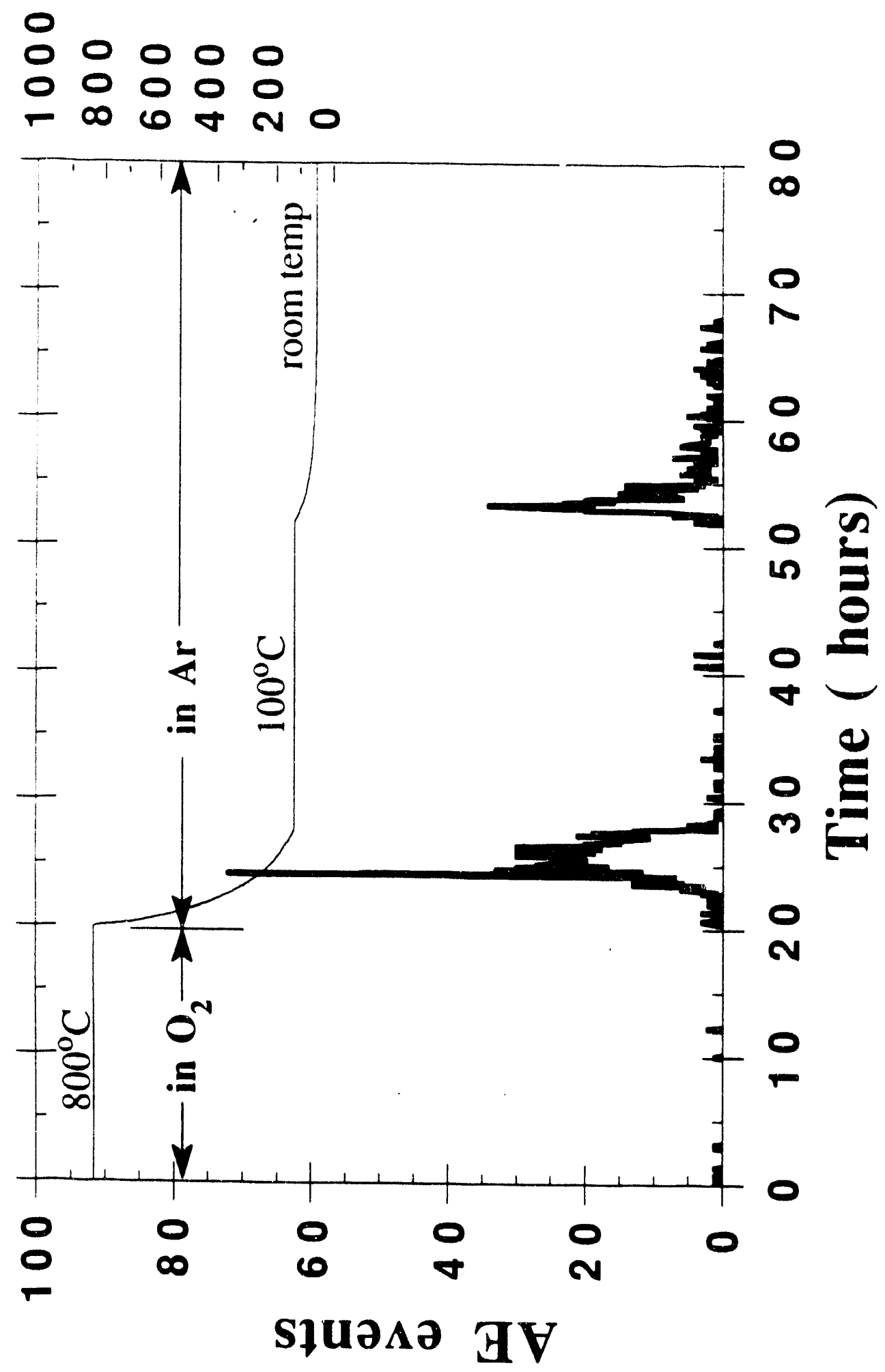

ذす

可 次苟

咅呈 


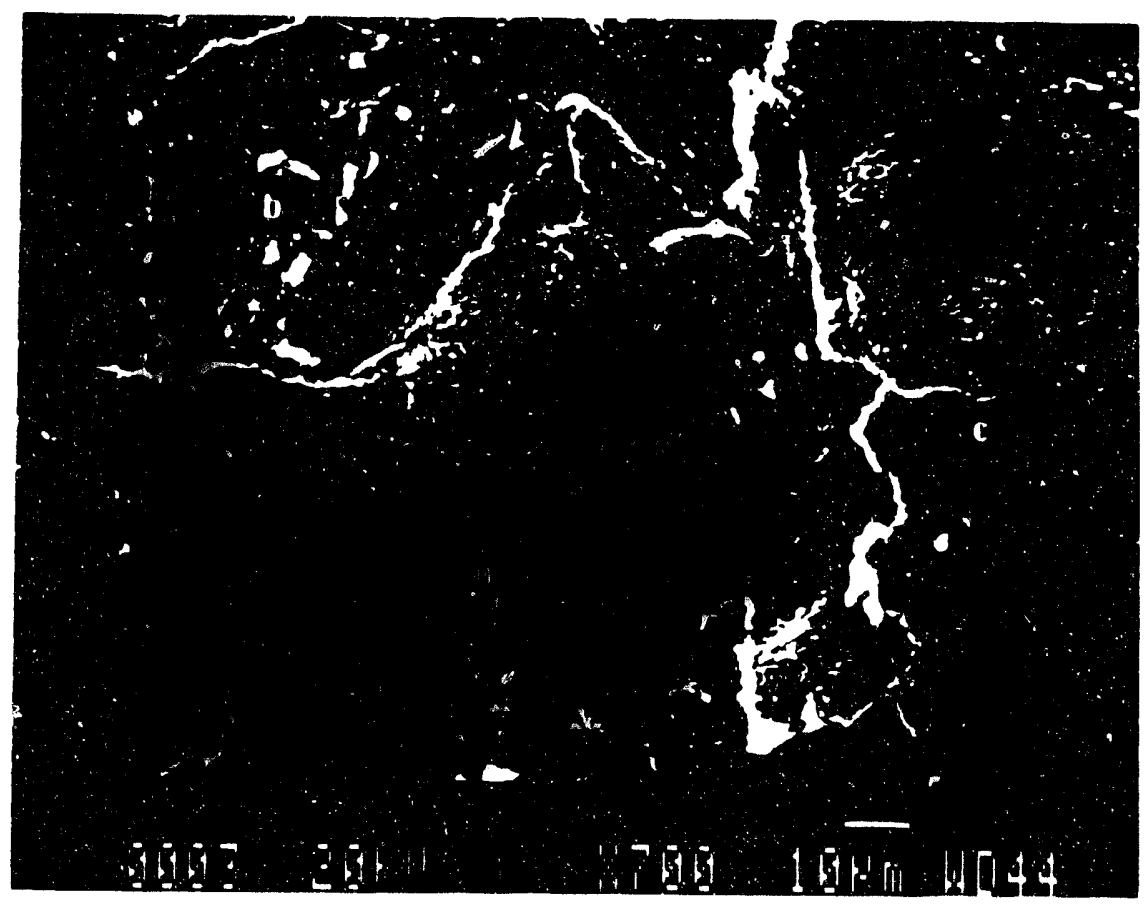

Figure 10. SEM micrograph of an oxidized 304 stainless steel illustrating the three characteristic scale regions: (a) intact (b) spalled and (c) cracked but intact. The sample was oxidized at $800^{\circ} \mathrm{C}$ and furnace cooled to room temperature. 

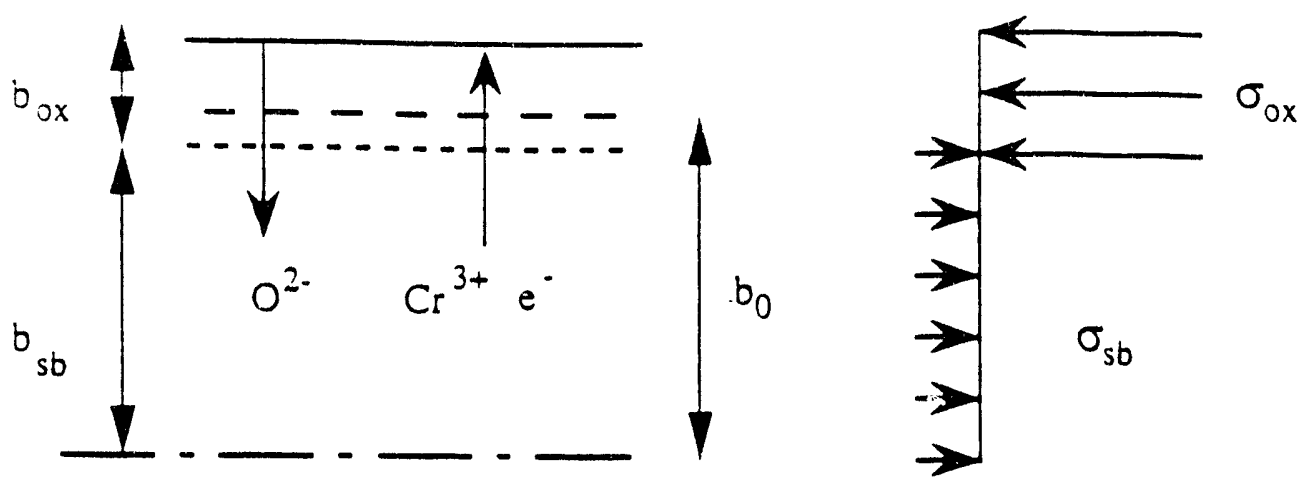

(a)

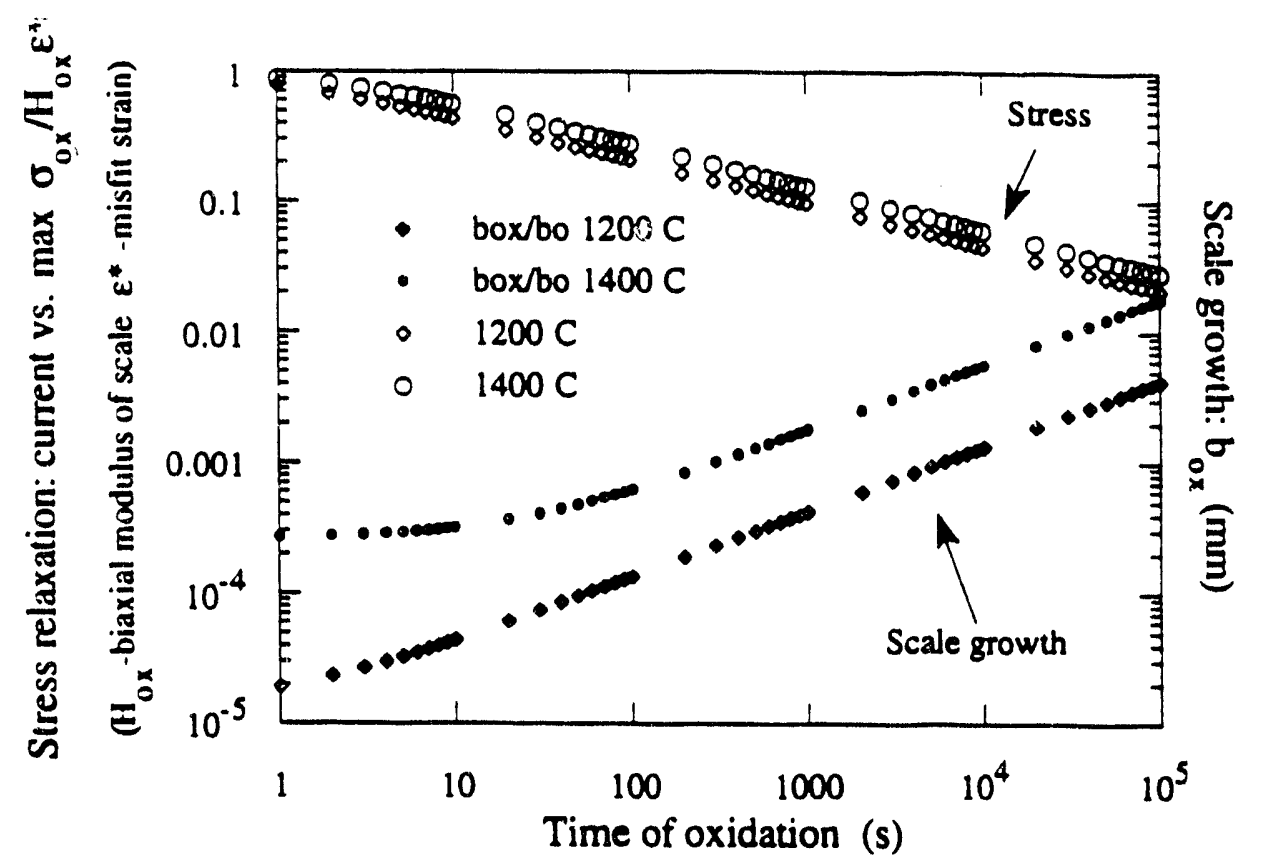

(b)

Figure 11. Schematic illustration of the oxide growth model (a). $b_{o x}$ and $b_{s b}$ define the oxide and substrate thick ress, $b_{0}$ denotes the original substrate thickness. The mechanical stress balance assumed for the model is illustrated in (b). 


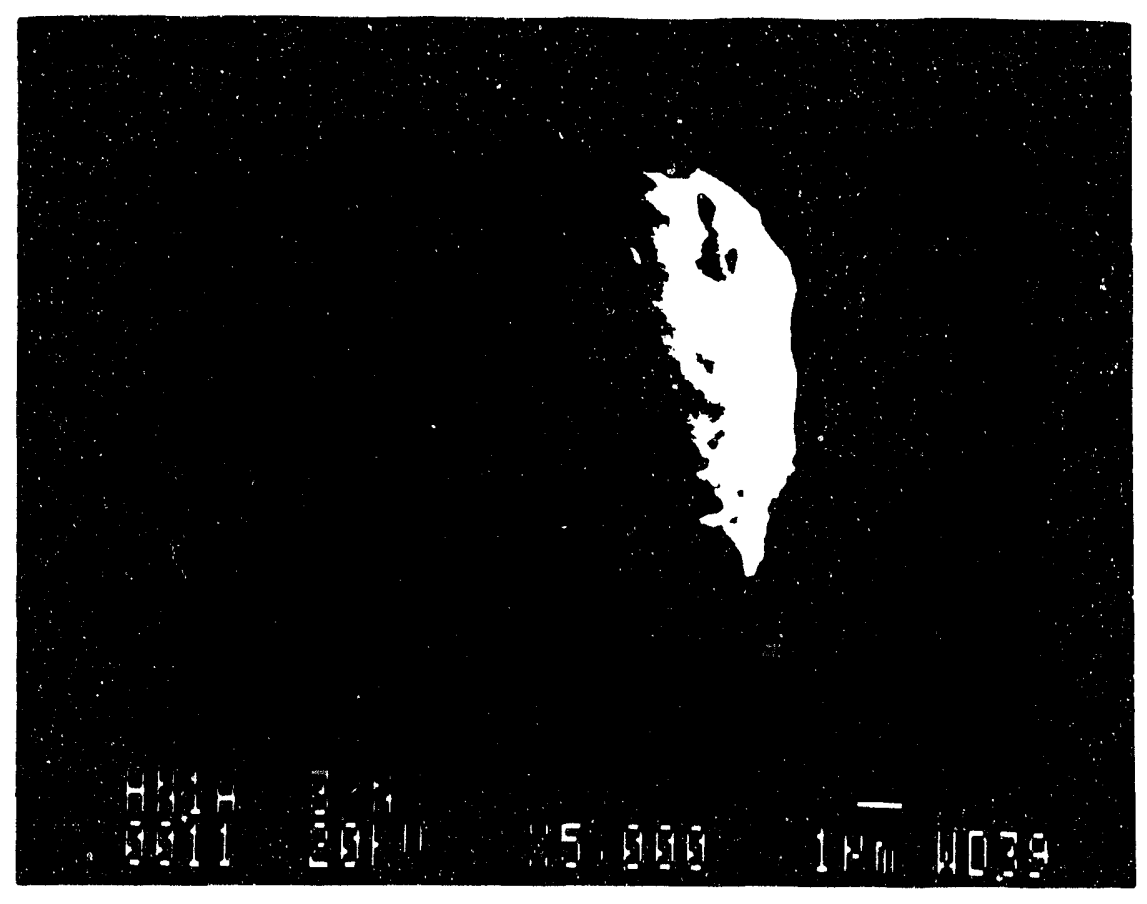

Figure 12. SEM micrograph of nano-indentation on $\mathrm{NiO}$ grown on $\mathrm{Ni}$. Indentation has caused intergranular fracture in the oxide and severe plastic deformation of the Ni substrate.

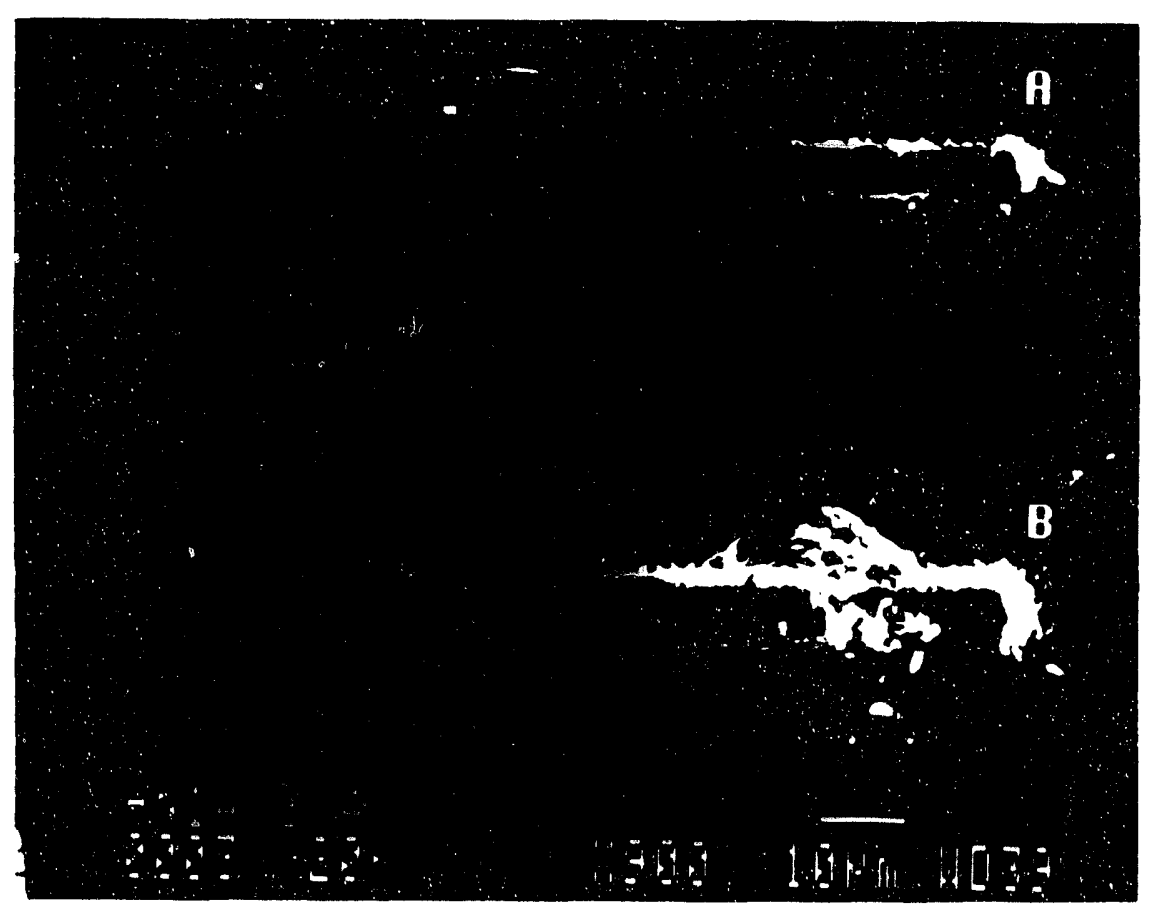

Figure 13. SEM micrograph of two scratch tracks on the NiO scale. The cracks within the indentor track, and perpendicular to the scratch path, are indicative of Mode I fracture. Localized oxide spallation has occurred on the track B. 

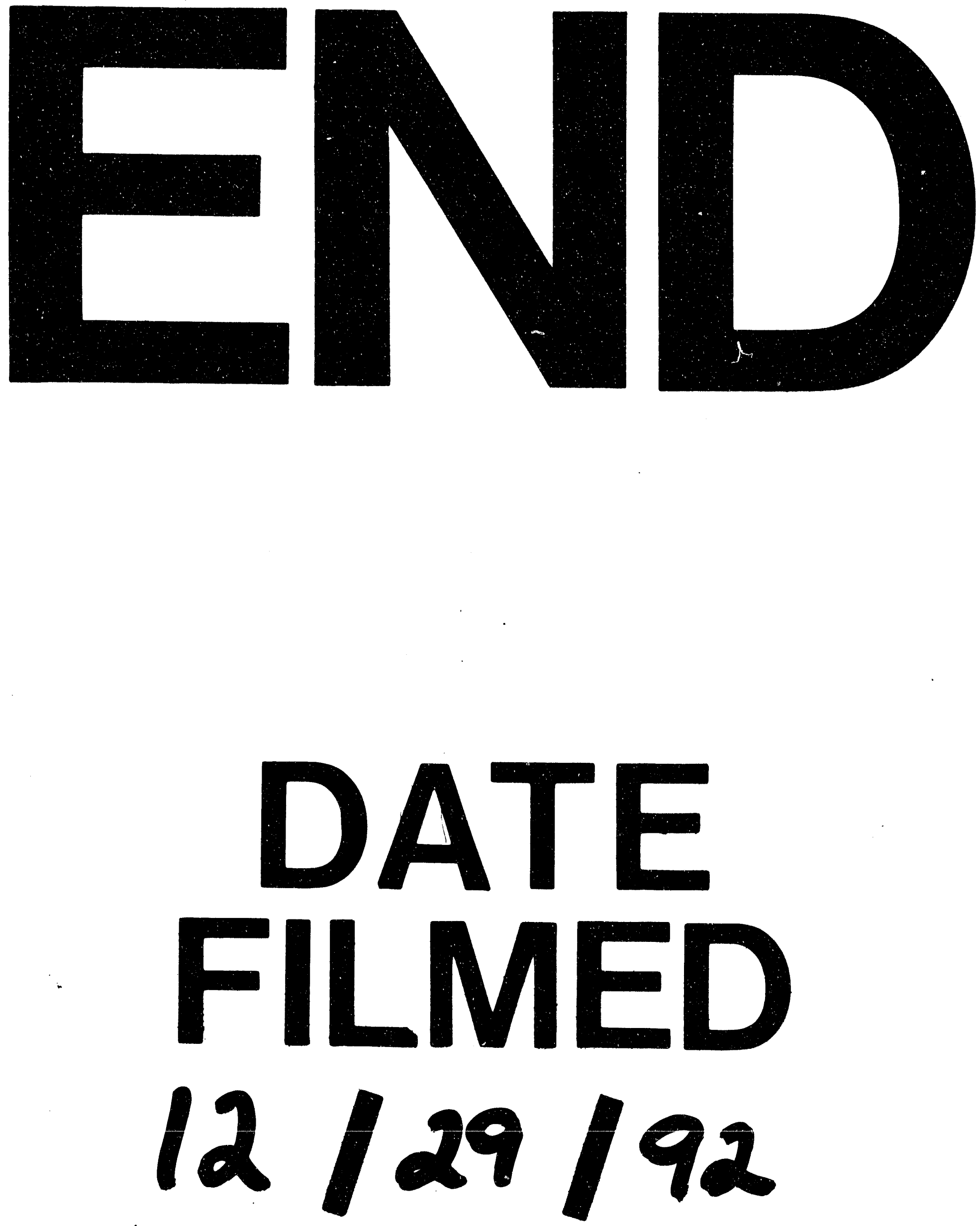
